\title{
Assessment of Water Pollution in a Heavily Polluted Area of the Taihu Lake Basin
}

\author{
Bo Bian \\ Department of Key Research Project \\ Jiangsu Provincial Academy Of Environmental Science \\ Nanjing, China \\ bianbo1@163.com
}

\author{
Hai suo $\mathrm{Wu}$ \\ Department of Key Research Project \\ Jiangsu Provincial Academy Of Environmental Science \\ Nanjing, China \\ Whs@ jshb.gov.cn
}

\begin{abstract}
The water quality and eutrophication status of Taihu Lake in recent years are presented and the pollution trends are analyzed. Meiliang Bay, Zhushan Bay, and the upstream catchment area of the Taihu Lake Basin cover the major upstream rivers flowing into a heavily polluted area in the lake. Water pollution were found in the heavily polluted area, including unreasonable industrial structure and layout, high percentage of secondary industry, especially, excessive pollutants containing nitrogen and phosphorus are being discharged. high percentage of ammonia nitrogen in the major rivers going to the lake, serious pollution in the river branches, and poor quality of lake water. Result from this study provides a scientific basis for the comprehensive treatment of water environment in a heavily polluted area in the Taihu Lake basin and for the effective control of eutrophication in Taihu Lake.
\end{abstract}

key words : Taihu Lake Basin; heavily polluted area; comprehensive survey; serious pollution

\section{INTRODUCTION}

The Taihu Lake, located at the center of the Changjiang delta region, is one of the five well-known great freshwater lakes in China. The lake and its effluent rivers are important water sources for the 40 million inhabitants living around the area and the rapidly increasing industrial factories in Shanghai, Jiangsu, and Zhejiang. The pollutants originate mainly from agricultural nonpoint source pollution, which is widespread pollution from the overuse of fertilizers and pesticides in rural areas, as the Taihu Lake basin is a land with a steady fare of fish and rice. Compared with point source pollution, diffused pollution is much more complicated to treat and difficult to control. SS is the primary pollutant of the nonpoint source pollution in the basin, as approximately $80 \%$ of SS in the area comes from nonpoint source pollution (Zhang et al. 2010).

From the early 1980 s to the early 90 s, the average water quality of Taihu Lake decreased from Class II to Class III.Since the 90s, the incident of algal blooms has occurred frequently.Since the mid 90's, the average water quality of Taihu Lake decreased to Class V and even worse. The status changed from moderate eutrophication to moderate-light. Major pollutants are TN, and then TP. The permanganate index of the Lake remained at Class III, which was improved during the period of "11th Five-Year Plan". TN is the major pollution indicator of Taihu water quality, whose concentration is always at a high level and worse than Class $V$ for many years. It has been an important factor of water quality deterioration and increased eutrophication(Duan et al. 2009; ).

The major nutrient sources have been recognized as industrial activities, for example, sewerage, livestock drainage, soil nutrients and losses of fertilizers in drained agricultural lands (Lai et al. 2006) Zhang et al. 2001; Qin et al. 2007; Guo et al. 2004). These developments have caused a large increase in nutrient levels in the rivers that run into Taihu Lake, resulting in high levels of eutrophication (Jin et al. 2006; Guo, 2007; Qin et al. 2007). The algal bloom has long been recognized as the result of imported nutrients, mainly nitrogen and phosphorus (Plinski et al. 1999; Guo 2007).

Many disciplinary studies have been performed on the nutrient pollution issue (Wang et al. 2004), but no integrated assessment considering environmental, economic, source of pollutants, water quality and social indicators simultaneously has been carried out. The objective of this study is to perform an integrated assessment of the impacts of environmental, economic, source of pollutants, water quality and social indicators on nutrient pollution in Taihu Basin. This information provides the scientific basis for a comprehensive treatment of the water environment in the heavily polluted area and for the effective control of eutrophication in Taihu Lake basin.

\section{MATERIALS AND METHODS}

\section{A. Study region}

Taihu Lake has the functions of drinking, industrial and agricultural use, shipping, tourism, flood regulation and storage, etc. Mega-cities of Shanghai, 4 prefecture-level cities of Jiangsu Province (ie. Suzhou, Wuxi, Changzhou, Zhenjiang ), 3 prefecture-level cities of Zhejiang Province (ie. Hangzhou, Jiaxing, Huzhou), are distributed in this area. There are totally 210 rivers which have the access to Taihu Lake. COD emissions per unit land area are 9 times of the national average, while the COD emissions per unit output value is $30 \%$ of the national average. The heavily polluted area in Taihu Lake Basin refers mainly to the upstream catchment area of Zhushan Bay and Meiliang Bay of Taihu Lake. It covers six districts (i.e. 
Nanchang, Cong'an, Beitang, Huishan, Xinqu, and Binhu) in Wuxi City and Yixing City and five districts (i.e., Zhonglou, Tianning, Qishuyan, Xinbei, and Wujin) in Changzhou City, totaling 41 towns and 56 communities. The region has a total area of $5272 \mathrm{~km} 2$, accounting for $14 \%$ of the area of Taihu Lake Basin, as shown in the administrative division in Fig. 1.

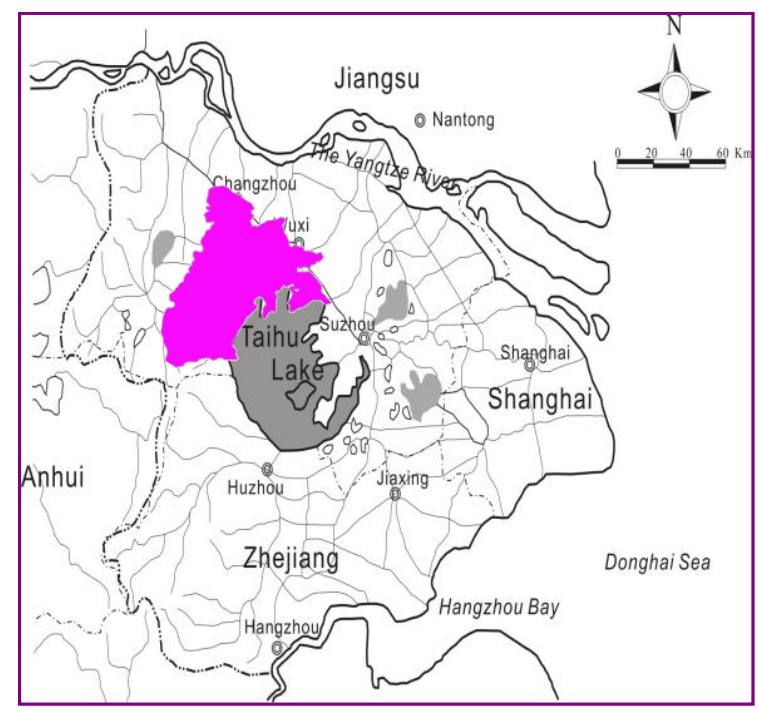

Fig. 1Administrative of heavily polluted area in Taihu Lake area

\section{B. Study methods}

This study examined the industrial structure, land use, source of pollutants, and water environment of 97 towns/communities by taking 2007 as the start year. The distribution of industrial structure has a direct influence on pollutant emission. Based on the Statistics Yearbook of the region, the changing trend and distribution features of the industrial structure from 2001 to 2008 were examined and analyzed. The emission concentration of nitrogen and phosphorus from the key enterprises in each industrial sector was verified based on environmental statistics data and the first national pollution source survey bulletin (Statistics Bureau of Jiangsu Province (SBJP), 2001-2010; Ministry of Environmental Protection the People's Republic of China, 2010).

\section{RESULTS AND DISCUSSION}

\section{A. Distribution of industrial structure}

Fig.2 shows the percentage of primary industry in the region dropping from $4.2 \%$ in 2000 to $2.0 \%$ in 2007, indicating a declining trend, and the percentage of the secondary industry dropping from $56.9 \%$ in 2000 to $55.7 \%$ in 2007, initially rising before declining. The extent of the variation is small, and the trend is gradual. The percentage of the tertiary industry increased gradually from $38.9 \%$ in 2000 to $42.3 \%$ in 2007 . The percentage of tertiary industry worldwide ranges from $70 \%$ to $80 \%$, whereas that in hub cities such as Beijing, Guangzhou, and Shanghai is above $45 \%$. By contrast, Taihu Lake Basin has an unreasonable distribution of industrial structure in the heavily polluted area, lower percentage of tertiary industry, and higher percentage of secondary industry. These factors hinder regional economy, structural adjustment, and industrial upgrade (State Council, 2008)

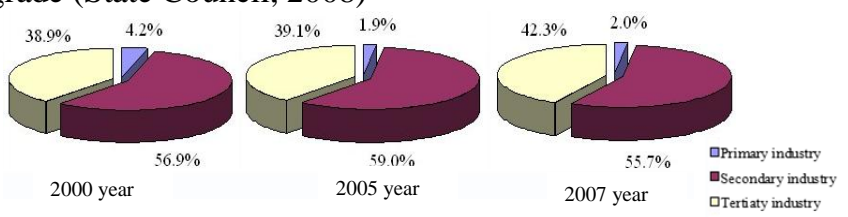

Fig. 2 Changing trend of primary, secondary, and tertiary industries in the heavily polluted area from 2001 to 2007

\section{B. Source of pollutants}

Four types of pollutants, i.e., industrial, urban communities, rural communities, and agricultural, were examined to determine the composition of pollutant sources in the region in 2007. As shown in Fig. 3, the total emission of pollutants COD, ammonia nitrogen, nitrogen, and phosphorus in the region were 110600, 11600, 21500, and 1500 tons, respectively, with focus on urban emission for the composition of pollutant indexes.

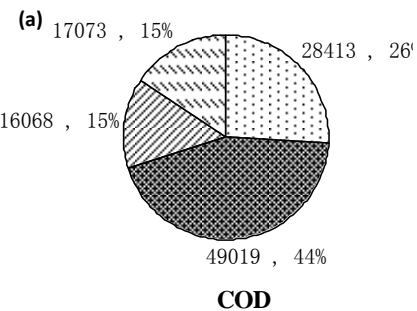

(c)

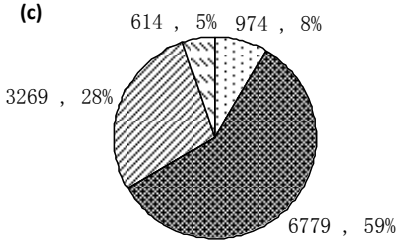

$\mathrm{NH}_{4}^{+}-\mathrm{H}$ (b)

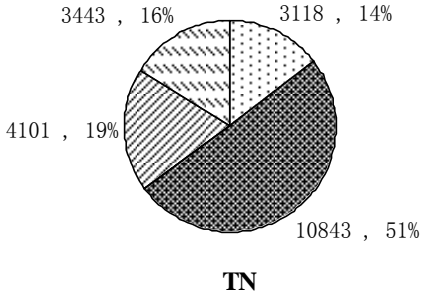

(d)

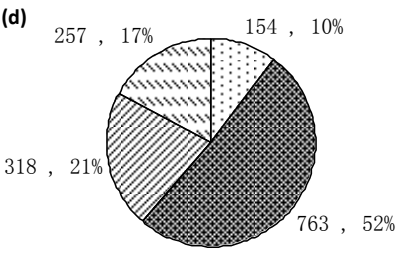

TP $\square$ industrial nollution source $\mathbb{Q}$ town domestic nollution source

: $\square$ agricultural pollution source $\square$ rural domestic pollution source Fig. 3 Pollutant emission compositions

This study examined 11023 enterprises, among which 5036 come from the six major industrial sectors (i.e., chemical, textile dyeing and finishing, steel and iron, plating, papermaking, and food processing) in Taihu Lake Basin, as determined by the Taihu Lake Region Sewage Plant and Key Industrial Sector Sewage Emission Limit Standard (Environmental Protection Department of Jiangsu Province, 2008), accounting for $45.7 \%$ of the total enterprises. In 2007 , the emission of industrial sewage in the region was about 243 million tons, COD was about $28400 \mathrm{t}$, ammonia nitrogen was about $974 \mathrm{t}$, total nitrogen was about $3118 \mathrm{t}$, and that of total phosphorus was about $154 \mathrm{t}$.

As shown in Table.1 and Table.2, the amount of sewage into lake-going rivers of primary, secondary, and tertiary industries in the heavily polluted area in 2007, COD was 49.96 million t/a, TP was 1.18 million $\mathrm{t} / \mathrm{a}, \mathrm{NH}_{4}{ }^{+}-\mathrm{H}$ was 4.63 million t/a.The emission of industrial sewage of primary, secondary, and tertiary industries in the heavily polluted area in 2007, 
COD was 31.79 million t/a, TP was 1.18 million t/a, $\mathrm{NH}_{4}^{+}-\mathrm{H}$ was 2.98 million t/a.

Table1 The amount of sewage into lake-going rivers of primary, secondary, and tertiary industries in the heavily polluted area in 2007 million t/a

\begin{tabular}{lcccc}
\hline Pollutants & Industry & Wu xi & Chang zhou & Total \\
\hline \multirow{4}{*}{$\mathrm{COD}$} & Primary industry & 6.27 & 13 & 19.27 \\
& Secondary industry & 2.65 & 2.01 & 4.66 \\
& Tertiary industry & 15.97 & 10.06 & 26.03 \\
& Total & 24.89 & 25.07 & 49.96 \\
& Primary industry & 0.9 & 0.83 & 1.73 \\
$\mathrm{NH}_{4}{ }^{+}-\mathrm{H}$ & Secondary industry & 0.13 & 0.08 & 0.21 \\
& Tertiary industry & 1.61 & 1.08 & 2.69 \\
& Total & 2.64 & 1.99 & 4.63 \\
& Primary industry & 0.33 & 0.4 & 0.73 \\
$\mathrm{TP}$ & Secondary industry & 0.04 & 0.04 & 0.08 \\
& Tertiary industry & 0.22 & 0.15 & 0.37 \\
& Total & 0.59 & 0.59 & 1.18 \\
\hline
\end{tabular}

Table 2 The emission of industrial sewage of primary, secondary, and tertiary industries in the heavily polluted area in 2007 million $\mathrm{t} / \mathrm{a}$

\begin{tabular}{ccccc}
\hline Pollutants & Industry & Wu xi & Chang zhou & Total \\
\hline \multirow{4}{*}{ COD } & Primary industry & 2.38 & 5.46 & 7.84 \\
& Secondary industry & 2.38 & 1.81 & 4.19 \\
& Tertiary industry & 12.02 & 7.73 & 19.75 \\
& Total & 16.78 & 15 & 31.78 \\
& Primary industry & 0.32 & 0.29 & 0.61 \\
$\mathrm{NH}_{4}{ }_{4}^{+}-\mathrm{H}$ & Secondary industry & 0.11 & 0.07 & 0.18 \\
& Tertiary industry & 1.31 & 0.88 & 2.19 \\
& Total & 1.74 & 1.24 & 2.98 \\
& Primary industry & 0.12 & 0.16 & 0.28 \\
$\mathrm{TP}$ & Secondary industry & 0.04 & 0.03 & 0.07 \\
& Tertiary industry & 0.18 & 0.12 & 0.3 \\
& Total & 0.34 & 0.31 & 0.65 \\
\hline
\end{tabular}

The urban population of 4.54 million of this region produced 306 million tons/year domestic sewage, and the rural population of 2.9 million produced 85 million tons/year domestic sewage annually. The emission of COD, ammonia nitrogen, total nitrogen, and total phosphorus in the urban area was 49000, 6800, 10800, and 760 tons annually, respectively. In the rural area, the emission of COD, ammonia nitrogen, total nitrogen, and total phosphorus was 16100, 3300, 4100, and 320 tons, respectively. This study examined the types of land plantation, plantation area, application of fertilizers, types and number of livestock and poultry, types of farms, forms, outgoing direction and receiving waters of pollutants, types and areas of aquaculture, and types of feedstuff. The emission of COD, ammonia nitrogen, total nitrogen, and total phosphorus among the widespread pollutants in agriculture was 33100, 3900, 7500, and 580 tons, respectively. COD, ammonia nitrogen, and total phosphorus mainly come from plantation, livestock, and poultry feeding, and total nitrogen is mainly from plantation, accounting for $81.6 \%$ of the total emission.

\section{Quality of water environment}

The river system in the region flows generally from north to south and from west to east. Water coming from the north originates from Jinghang Grand Canal, and water coming from the west originates mainly from Ge Lake. Most of the water converges into the lake. Other rivers going to the lake include Taihuge Canal, Caoqiao River, Yincungang, Hengtang River, Yapugang, Wujingang, and Zhihugang. Wujingang and Zhihugang enter into Meiliang Bay, and the other rivers run to Zhushan Bay, as shown in Fig. 4. According to the assessment of COD, ammonia nitrogen, and total phosphorus water quality factor, Inferior Class V sections accounted for $67 \%$, Class V for $18 \%$, and Class IV for $11 \%$. Only $4 \%$ of the sections met the Class III water quality criteria, as shown in Fig. 9. The sections with the permanganate index classified as Class IV accounted for $98.18 \%$, with the ammonia nitrogen index classified as Class V (accounting for 50.91\%) and total phosphorus classified as Inferior Class $\mathrm{V}$ (accounting for $52.3 \%$ ). The region has serious pollution problems in its river networks, and the major pollution factors are ammonia nitrogen and total phosphorus (Environmental Monitoring Center of Jiangsu Province, 2005-2009).

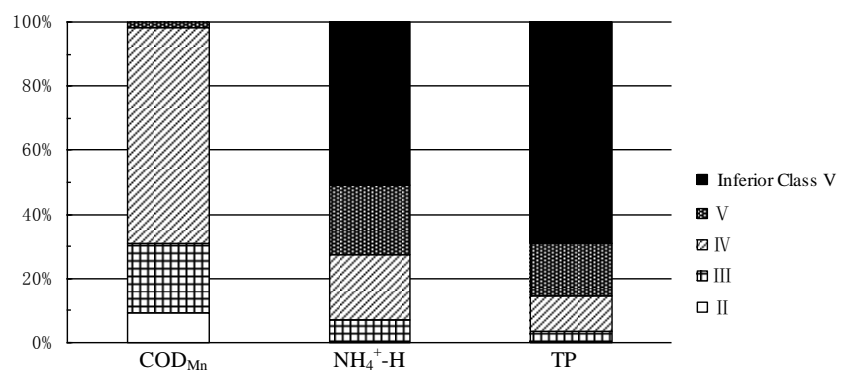

Fig. 4 Classification of water quality of the major lake-going rivers

\section{TLIc (Variation tendency of comprehensive trophic level index)}

TLIc was adopted to evaluate the Taihu Lake eutrophication status from 1994 to 2007. PI, TP, TN, Chla (chlorophylla), and WT (water transparency) were chosen to calculate for TLIc. The TLIc variation tendency is shown in Fig.5. Taihu Lake has been basically in the status of eutrophication since 1994, and its nutrition level has exhibited only slight fluctuations during the past ten years.However, the degree of eutrophication of Taihu Lake has increased recently and has reached the medium eutrophication level. The mean value of TLIc in 2007 was 61.35 , close to the lower limit of medium eutrophication. On the other hand, TLIc changed by month in 2007 and the peak value appeared in May and June (Fig.6). The maximum of 67.12 was found in June. The maximum of 67.12 was found in June. Correspondingly,,Chla concentration dramatically increased in May and June, and the maximum value was obtained in June, which contributed to the increase in TLIc. 


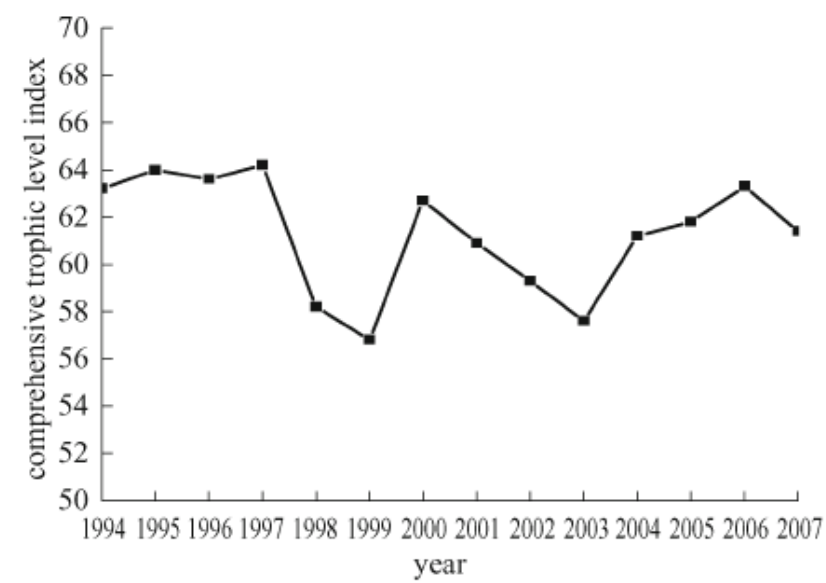

Fig. 5 Trend of index of eutrophication from 1994 to 2007

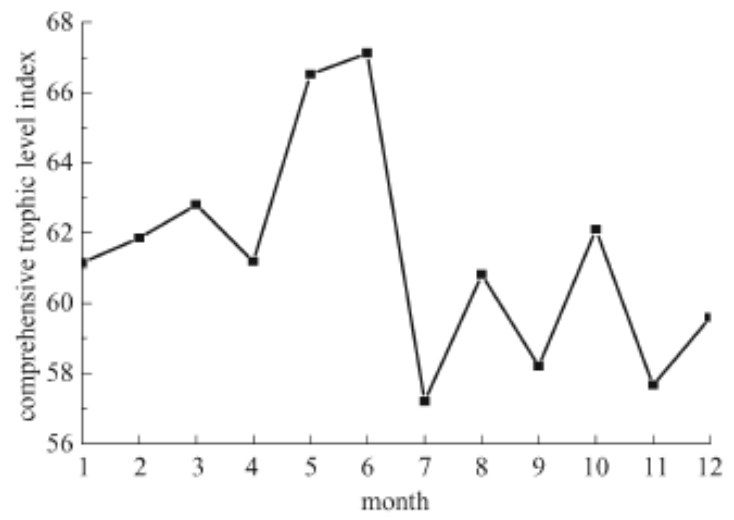

Fig. 2 Average comprehensive trophic level index (TLIc) of Taihu Lake

Fig. 6 Per month average comprehensive trophic level index(TLIc) of Taihu Lake in 2007

\section{CONCLUSIONS}

Unreasonable industrial structure and layout and high percentage of secondary industry. The total emission of pollutants COD, ammonia nitrogen, nitrogen, and phosphorus in the region were $110600,11600,21500$, and 1500 tons, respectively, with focus on urban emission for the composition of pollutant indexes. The sections with the permanganate index classified as Class IV accounted for $98.18 \%$, with the ammonia nitrogen index classified as Class V (accounting for 50.91\%) and total phosphorus classified as Inferior Class $\mathrm{V}$ (accounting for $52.3 \%$ ). The region has serious pollution problems in its river networks, and the major pollution factors are ammonia nitrogen and total phosphorus

\section{ACKNOWLEDGMENT}

This work was supported by the National Water Pollution Control and Management Technology Major Projects (No. 2012ZX07506-001), Key Technology R\&D Program of Jiangsu Province (No.BE2011809) and Natural Science Foundation of Jiangsu (No. BK2012883).

\section{REFERENCES}

[1] Duan, H., T., Ma, R., H., \& Xu, X., F.Two-Decade Reconstruction of Algal Blooms in China's Lake Taihu. Environ. Sci. Technol, 2009, 43, 3522-3528.

[2] Guo, L. 2007.Doing battle with the green monster of Taihu Lake Science, 317, 1166.

[3] Guo, H.Y., Zhu, J.G., Wang, X.R., Wu, Z.H., \& Zhang, Z. Case study on nitrogen and phosphorus emissions from paddy field in Taihu region. Environ. Geochem. Health,2004.,26, 209-219.

[4] Jin, X., Gao, J., \& Zhao, G. Impacts of 20-year socio-economic development on the trend of aquatic environment of the Taihu Lake Basin. Resour. Environ, Yangtze Basin, 2006.,3, 298-230.

[5] Lai, G.; \& Yu, G. A. Numerical Simulation of Nutrient Transport in Taihu Basin. In Hydrology and Management of Forested Wetlands Proceedings of the International Conference; The American Society of Agricultural and Biological Engineers: New Bern, NC, 2006,325-340.

[6] Plinski, M., \& Jozwiak, T. Temperature and N: P ratio as factors causing blooms of blue-green algae in the Gulf of Gdansk. Oceanologia, 1999.,41 (1), 73-80.

[7] Qin, B. Q., Xu, P. Z., Wu, Q. L., Lian, C. L., \& Zhang, Y. L. Environmental issues of Lake Taihuhu, China. Hydrobiologia, 2007,581, 3-14

[8] Statistics Bureau of Jiangsu Province (SBJP). Jiangsu statistics almanac. Beijing: China statistics Press (in Chinese). 20012010.,pp.105-186.

[9] State Environmental Protection Administration. Environmental Quality Standards for Surface Water, (GB3838-2002), Beijing: China Environmental Science Press (in Chinese). 2002,pp.3-6.

[10] State council. Overall program of Taihuhu Lake Basin Water Environment Comprehensive Management. Beijing: China Environmental Science press (in Chinese). 2008, pp.52-70.

[11] Yang, G. S., \&Wang, D. J. Economical development, water environment and water calamity Taihu basin, Beijing: Science press (in Chinese) 2003, pp. 26-32.

[12] Zhang QL, Chen YX, Jilani G, Shamsi IH, Yu QG Model AVSWAT apropos of simulating non-point source pollution in Taihu lake Basin. J Hazard Mater ,2010, 174: 824-830

[13] Zhang, Y. M., Zhang, Y. C., Gao, Y. X., Zhang, H. H., Cao, J. Y., Cai, J. B., \& Kong, X. J. Water pollution control technology and strategy for river-lake systems: a case study in Gehu Lake and Taihuge Canal. Ecotoxicology, 2011, 20, 1154-1159.

[14] Zhang, W., Wang, X., Jiang, Y.. Effect of emission control on water quality of the Taihu Lake. Rural Eco-Environ, 2001,17,44-47. 